\title{
REFLEXÕES SOBRE O ENSINO DE LÍNGUA PORTUGUESA EM CONTEXTO INDÍGENA
}

\author{
Marina Oliveira Barboza Brandão (PPGEL/UEL- \\ marinaleib@hotmail.com)
}

\begin{abstract}
RESUMO: Este trabalho tem como objetivo apresentar os resultados de uma pesquisa que teve como finalidade diagnosticar, compreender e refletir sobre o ensino de língua portuguesa no contexto bilíngue de uma escola indígena de uma reserva indígena da região de Dourados/MS. Sabe-se que o Referencial Curricular Nacional para as Escolas Indígenas/RCNEI, bem como outros documentos oficiais sobre educação intercultural indígena apontam para a garantia de educação intercultural, bilíngue e diferenciada para a população indígena. A língua caracteriza-se como objeto de poder e identidade de um povo, entretanto, no contexto indígena, a imposição do português como língua única está muito presente. Neste trabalho pretende-se apresentar as reflexões sobre as práticas de ensino e concepções de ensino e aprendizagem de língua portuguesa presentes na comunidade analisada. Assim, pretende-se colocar em evidência quais os conceitos de ensino de língua subjacentes nas escolhas e práticas docentes no contexto intercultural indígena da região. Nossa perspectiva teórica terá como norte as reflexões da Linguística Aplicada e as pesquisas em educação escolar indígena e ensino de língua portuguesa como segunda língua.
\end{abstract}

Palavras-chave: ensino; língua portuguesa; escola indígena

\begin{abstract}
This study aims to present the results of a research that aimed to diagnose, understand and reflect on the teaching of Portuguese in the bilingual context of an indigenous school of an Indian reservation in the region of Dourados/MS. It is known that the Referencial Curricular Nacional para as Escolas Indígenas/RCNEI, as well as other official documents about indigenous intercultural education, point to the guarantee of intercultural, bilingual and differentiated education for the indigenous population. Language is characterized as an object of power and identity of a people, however, in the indigenous context, the imposition of Portuguese as a second language is very present. This paper intends to present the reflections on teaching practices and conceptions of teaching and learning of Portuguese language present in the analyzed community. Thus, it is intended to highlight the concepts of language teaching underlying the choices and practices of teachers in the indigenous intercultural context of the region. Our theoretical perspective will focus on the reflections of Applied Linguistics and the research on indigenous school education and Portuguese language teaching as a second language.
\end{abstract}

Keywords: teaching; portuguese language; indigenous school

\section{INTRODUÇÃO}

A Escola Municipal Indígena em que se deu a pesquisa ${ }^{1}$ está localizada em uma das reservas indígenas da cidade de Dourados. É cortada por uma rodovia e não há pavimentação asfáltica, de modo que, quando chove, as crianças não conseguem deslocar-se até a escola. Possui cerca de 779 alunos matriculados, segundo informações da coordenação da escola no

\footnotetext{
1 As reflexões aqui apresentadas são resultado de uma pesquisa realizada no curso de Especialização em Educação Intercultural Indígena - FAIND/UFGD em 2015.
} 
momento da pesquisa. Oferece turmas de Pré, $1^{\circ}$ ao $5^{\circ}$ ano e $6^{\circ}$ ao $9^{\circ}$ ano. Cerca de $48 \%$ dos alunos da escola estão matriculados entre o $1^{\circ}$ e $5^{\circ}$ ano.

Para o trabalho de pesquisa, foram destinadas 50 h/a de observações nas aulas de língua portuguesa. Foram feitos registros escritos em diário de bordo, e coleta de avaliações e atividades realizadas em sala de aula, além de entrevistas.

A intenção era verificar como se dava o ensino de língua portuguesa nessa escola indígena, visto que, em contato com alguns professores indígenas, estes disseram que as crianças indígenas sofrem preconceito de professores não indígenas por não saberem se comunicar em português "correto".

A escola escolhida tem um público em que a maioria das crianças é falante da língua indígena, contudo, ao ingressarem na escola, aos poucos vão aprendendo o português e deixando de falar a LI na escola e na comunidade.

Desse modo, a pesquisa pretendeu verificar como os direitos e o reconhecimento de especificidades linguísticas são aplicados na escola, tendo em vista ser uma escola indígena.

Com base num contexto histórico, apontamos, a seguir, algumas considerações sobre os avanços e conquistas da população indígena quanto ao direito de ter uma escola bilíngue e diferenciada.

A Constituição Federal de 1988 trouxe ganhos em relação aos direitos indígenas, como podemos constatar em seus artigos 231 e 232, reconhecendo-lhes o direito à sua organização social, costumes, línguas e tradições (BRASIL, 1988). Com isso, uma nova fase da história da Educação Escolar Indígena (EEI) se inicia com a inserção gradativa da educação indígena nas escolas das comunidades indígenas. Nesse sentido, diversos aparatos jurídicos foram sendo criados para regulamentar a construção de EEI específica, diferenciada, autônoma, bilíngue e intercultural. Entre os documentos, destaca-se a elaboração do Referencial Curricular Nacional para as Escolas Indígenas/RCNEI (BRASIL, 1998), cujo objetivo era estabelecer parâmetros para a construção de currículos, de fato, diferenciados. O RCNEI, além disso, reforça a legitimação de direitos dos povos indígenas quanto aos direitos entendidos como coletivos:

São direitos coletivos dos povos indígenas, entre outros, o direito ao seu território e aos recursos naturais que ele abriga, o direito a decidir sobre sua história, sua identidade, suas instituições políticas e sociais, e o direito ao desenvolvimento de suas concepções filosóficas e religiosas de forma autônoma. A elaboração de normas jurídicas internacionais para os povos indígenas vem obrigando países e organismos internacionais a repensar muitas das concepções tradicionais sobre os direitos humanos (BRASIL, 1998, p. 30). 
A proposta de uma educação diferenciada tem por objetivo fortalecer e valorizar as identidades inerentes aos povos indígenas que, durante toda a história de contato, tiveram que resistir às políticas de dominação e, por meio da apropriação e ressignificação dos novos espaços educacionais, eles podem promover novas relações sociais.

Para a efetiva construção de um espaço escolar indígena, o Conselho Nacional de Educação, em 1999, discutiu e apontou as diretrizes nacionais para a educação escolar indígena, assim reconhecendo a categoria escola indígena e não mais escola rural (Resolução 03/1999). Desse modo, é possível uma nova organização e a criação de Projeto Pedagógico Curricular - PPC próprio e a participação da comunidade indígena na definição e organização da escola. Além disso, reconhece-se a importância de uma formação específica para os professores indígenas.

No que diz respeito ao acesso à língua portuguesa, percebe-se que essa possibilidade constituiu para o indígena um meio importante para o acesso aos conhecimentos universais e ferramenta que lhes garante certo poder para reivindicar seus direitos, visto que a língua é uma ferramenta de representação social, é por meio da língua (gem) que as pessoas se inserem no campo social. Os indígenas, no contexto apresentado, são majoritariamente falantes de língua indígena numa sociedade de falantes de português, assim precisam se comunicar em língua portuguesa em diversas esferas públicas, sejam hospitais, delegacias, cartórios, etc. Isso exige um conhecimento da língua para melhor entender as leis e as situações escritas e/ou faladas que envolvem o contato nesses campos.

Tanto o RCNEI (BRASIL, 1998), quanto a LDB (BRASIL, 1996) acenam para um ensino significativo da língua portuguesa, seja em contexto indígena ou não, bem como asseguram o direito de decidir e planejar como deve ser o ensino de língua na comunidade.

Segundo a LDB/96, Artigo 32, § $3^{\circ}$ (BRASIL, 1996, p.11): “O ensino fundamental regular será ministrado em língua portuguesa, assegurada às comunidades indígenas a utilização de suas línguas maternas e processos próprios de aprendizagem”. O Referencial Curricular Nacional para Escolas Indígenas diz que:

É por meio do uso da linguagem que a maneira de viver de uma sociedade é expressa e passa, constantemente reavaliada, de uma geração para outra. Os modos específicos de usar a linguagem são, por isso, como documentos de identidade de um povo num determinado momento de sua história (BRASIL, 1998, p. 113). 
A língua portuguesa para o indígena da região de Dourados assume importância tal que passa a se tornar o seu domínio uma questão de sobrevivência, tanto do ponto de vista econômico quanto social, num contato cada vez mais intenso com o não-indígena da região.

Embora essa apropriação da língua não indígena traga-lhes alguns benefícios, a forma como ela passa a fazer parte da vida do indígena acaba contribuindo para um processo de deslocamento da língua materna. É importante lembrar que a língua indígena não é apenas um código no qual se comunicam, mas um lócus de conhecimento cultural e histórico desse povo. Ao ser abandonado ou estigmatizado, esse conhecimento corre o risco de desaparecer com o tempo.

As comunidades indígenas buscam, então, por meio da educação, alcançar espaços e posições que lhes foram negadas ao longo da história de colonização a qual muitos povos ainda estão submetidos, seja pelos discursos ou pelas práticas sociais de preconceito racial e estigmatização de tudo aquilo que não se encaixa no padrão hegemônico da sociedade.

Tendo em vista os documentos que garantem uma educação diferenciada, nos propomos a observar como acontece essa educação diferenciada no ensino de língua, especificamente o de língua portuguesa, em uma escola indígena da região. Na comunidade em questão, quase todos são falantes da língua indígena, e as crianças, em fase de alfabetização, quando chegam à escola, são basicamente monolíngues em Língua Guarani ou em Língua Kaiowá. Com o passar dos anos escolares, as crianças vão aos poucos deixando de utilizar a língua indígena na escola. Assim, um dos objetivos foi o de entender como é a relação dos professores e dos alunos com o ensino e aprendizagem da Língua Portuguesa. Inicialmente, acreditávamos que o português era ensinado como segunda língua e/ou que fosse tratado de modo diferenciado, tendo em vista o público bilíngue.

\section{EDUCAÇÃO ESCOLAR INDÍGENA}

A Educação Escolar Indígena sofreu ao longo dos anos diversas mudanças desde a Constituição Federal de 1988 que reconheceu aos povos indígenas seus direitos como cidadãos da nação brasileira, bem como seus costumes, línguas e crenças. Bruno (2011) afirma que esse reconhecimento foi acompanhado de políticas e mudanças na gestão escolar para esses povos. Assim, o MEC, em 1991, quando a Educação Escolar Indígena deixa de ser responsabilidade da FUNAI, delega às secretarias Estaduais e Municipais a responsabilidade de planejar políticas que atendam a esses povos. Várias leis e documentos foram criados, 
desde então, no sentido de garantir a educação diferenciada, tais como: Portaria do MEC, n. 559 de 16 de abril de 1991, que garante aos povos indígenas educação escolar laica, diferenciada e que fortaleça seus costumes e tradições, línguas e modos próprios de aprendizagem; as Diretrizes para a Política Nacional de Educação Escolar Indígena do MEC em 1993; A Lei de Diretrizes e Bases da Educação Nacional em 1996; o Referencial Curricular Nacional para as Escolas Indígenas em 1998; o Parecer 14/99; a Resolução nº 03 de 1999; o PNE 2001; Referenciais para Formação de Professores Indígenas em 2002; o Decreto que cria os territórios Etnoeducacionais em 2009; as Diretrizes Curriculares Nacionais para a Educação Escolar Indígena na Educação Básica em 2012; as Diretrizes Curriculares Nacionais para a Formação de Professores Indígenas em cursos de Educação Superior e de Ensino Médio, RESOLUÇÃO CNE/CP nº1, 2015. Publicado no D.O.U. em 05/01/2015, Seção 1. p. 11, entre outros.

Nesse sentido, Bruno (2011) aponta para relatos de desrespeito às especificidades garantidas como direito à educação escolar indígena, tais como desrespeito aos calendários escolares específicos, festas indígenas sendo direcionadas para dias específicos da semana para atenderem necessidades dos calendários da gestão escolar tradicional, entre outras.

Outro ponto conflitante é a avaliação. Como avaliar respeitando as características da educação indígena dentro da educação escolar indígena, que acaba sendo norteada pela educação escolar não indígena? Bruno (2011) registra um relato de professor indígena sobre esse tema: "temos que enviar as avaliações dos alunos a cada dois meses para a diretoria de ensino, mas nós não queremos dar notas aos alunos, isto não faz sentido para nós. Cada criança tem o seu tempo para aprender” (Bruno, 2011, p. 645).

Nesse sentido, observa-se que as políticas públicas vão interferindo no modo de vida dentro da aldeia, produzindo posicionamentos políticos e ideológicos, ou seja, vão se construindo novas possibilidades, novas identidades, novos conflitos.

A escola não indígena é engessada em seu currículo e em suas concepções de aprendizagem e ensino, além disso, é uma escola vigilante e que muitas vezes inibe ações diferenciadas:

o que os professores indígenas dão em sala de aula é vigiado, conferido se está conforme, igual ao que está no sistema de conteúdos on line da secretaria de educação. $^{2}$

\footnotetext{
${ }^{2}$ Informação verbal sobre fala de professor indígena.
} 
Como falar em educação escolar indígena e garantir que sua característica principal, a da especificidade, seja respeitada se a escola ainda segue modelos rígidos, se não permite a flexibilização de conteúdos, de modos de aprender e de fazeres diferenciados?

Bruno (2011, p. 647) aponta que muitas vezes as políticas para os povos indígenas não são respeitadas: "os gestores das políticas julgam ser eles os agentes mais indicados para estabelecer prioridades e definir padrões de excelência relativos aos processos e resultados da educação indígena".

Assim, em muitos casos, os indígenas são chamados a participar da construção escolar, mas apenas para dar uma aparência democrática, pois, na verdade, são as diretrizes já préestabelecidas que definem o que, como e onde serão implementadas tais políticas.

Outro aspecto é o fato de que muitas comunidades e povos indígenas não tenham pedido uma Educação Escolar Indígena, muitos não aceitam o ensino proposto pelo Estado:

o que se observa é que entre os próprios índios não há consenso acerca da importância da educação diferenciada (...) essa situação se verifica tanto entre as diferentes etnias indígenas existentes no País quanto no interior de um mesmo grupo ou aldeia. Há inclusive aqueles que rejeitam a escola e cujos filhos não a frequentam (BRUNO, 2011, p. 648).

Sabe-se que a rejeição a uma escola diferenciada é fruto dos processos de colonização que construíram um discurso da inferiorizarão da cultura indígena e uma supervalorização da cultura ocidental. Assim, cabe a escola e aos gestores refletirem sobre esses posicionamentos com a comunidade, tentando identificar nesses discursos as nuances do poder colonizador.

Nesse sentido, muitos conflitos surgem dentro das comunidades indígenas, conflitos linguísticos, culturais e ideológicos que devem ser administrados pela gestão escolar. Segundo Mello e Rojas (2012), a gestão escolar vai muito além de planejar, coordenar, dirigir e avaliar, pois implica redimensionar os saberes individuais e coletivos enfrentados diariamente.

\section{REPRESENTAÇÕES SOBRE LÍNGUA PORTUGUESA NA ESCOLA INDÍGENA}

A questão da língua indígena na comunidade analisada é interessante, visto que boa parte da população dessa comunidade ainda fala a língua indígena, contudo, é, ao mesmo 
tempo preocupante, pois a falta de políticas linguísticas ${ }^{3}$ que garantam seus direitos linguísticos faz com que a comunidade aos poucos possa deixar de falar sua própria língua.

Uma proposta bilíngue deveria considerar as necessidades linguísticas da comunidade indígena, de modo que, ao mesmo tempo, favorecesse a manutenção e uso de sua língua nos contextos exigidos. Assim, a escola indígena hoje vive um processo de descoberta quanto ao que realmente querem estabelecer como uma política indígena de educação e as políticas planejadas pelo estado.

Os professores indígenas também vivem uma contradição, como podemos constatar nos relatos $^{4}$ de alguns:

Se você abraça os conhecimentos tradicionais, alguns falam que é retrocesso. Se abraça os conhecimentos ocidentais somos criticados porque abandonamos nossa cultura.

Muitos pais não aceitam o ensino de língua indígena, pois para o indígena os conhecimentos são para utilidade, querem trabalhar, estudar.

Essa confusão sentida pelos professores indígenas é parte de um processo de inculcação de valores alheios sobre a cultura indígena, além da falta de um trabalho efetivo nas escolas sobre interculturalidade, de modo que a construção dialógica entre as culturas fosse uma possibilidade factível.

Uma sociedade que educa para o mercado de trabalho dificulta o processo de formação integral do ser humano, pois este é considerado apenas como mão de obra, logo os currículos na escola obedecem a essas perspectivas mercadológicas e de desenvolvimento econômico e social. Sendo que desenvolvimento econômico não está atrelado aos conhecimentos tradicionais indígenas, daí o engano de comunidades indígenas acharem que os seus saberes são ultrapassados ou que não são para o desenvolvimento do seu povo ou de sua comunidade.

As contradições estão presentes nas falas dos professores, mas muitas posições são marcadas pelo discurso hegemônico. Assim, a necessidade que veem na educação pertence a um discurso ideologicamente marcado que diz que ter educação é ter escolaridade, e esta entendida como anos de acesso aos conhecimentos ocidentais legitimados historicamente. A sociedade acredita que estudar irá garantir o emprego, acesso a bens materiais, dentre outros acessos. Contudo, sabemos que essa afirmativa se constitui de mera falácia, visto que não há

\footnotetext{
${ }^{3}$ Definimos Política linguística como o estabelecimento de objetivos (sócio) linguísticos, a partir de uma escolha consciente, quanto à forma de concretização dos mesmos (MONSERRAT, 2006).

${ }^{4}$ Informação verbal sobre fala de professores indígenas.
} 
espaço para todos, e que ter um grau de escolaridade não garante acesso aos bens simbólicos, não é garantia de empregabilidade para todos.

Maher (2010) em citação a Ozolins (1996) e Rampton (1995) assinala a importância de se investigar o que as línguas significam para os sujeitos da pesquisa, investigando, assim, suas identidades linguísticas como construções fluídas e temporárias.

Segundo Maher (2010), é preciso pensar em quais representações emergem das práticas discursivas dos sujeitos, ou seja, deve-se pensar sobre como se configuram suas identidades étnicas e linguísticas. $\mathrm{O}$ ensino de língua portuguesa em um contexto indígena traz à tona questões de múltiplas complexidades. Dentre elas, as relações de poder assimétricas estabelecidas na linguagem. Segundo Maher (1994):

O índio tende a ocupar, já de partida, um lugar desvantajoso na interação, não só necessariamente, voltamos a afirmar, porque tem que se mover, linguisticamente falando, "em terreno alheio", mas também porque a desigualdade de poder entre ele e seu interlocutor se manifestará na e através da linguagem, afetando o teor da conversação (MAHER, 1994, p.72).

O ensino de português nas escolas não indígenas caracteriza-se como ferramenta de poder e mesmo entre os não índios tem-se o mito de que não sabemos o português. Contudo, o português que se deseja falado e escrito é aquele português formal, baseado em normas gramaticais tradicionais, desse modo, exclui-se a língua em uso, a língua em contextos étnicos e bilíngues, como no caso dos indígenas.

O Referencial Curricular Nacional Para as Escolas Indígenas - RCNEI orienta que a escola pense o currículo de forma diferenciada em cada comunidade, procurando refletir sobre questões, tais como: Que língua (s) deve (m) ser trabalhada (s) nesta escola? Que funções da linguagem podem ou devem ser trabalhadas? Em que línguas (s) oralmente ou por escrito? Ou das duas maneiras? Como se pode trabalhar estas funções de modo mais eficiente? (BRASIL, p. 113, 1998).

Seria necessária a criação de políticas linguísticas que garantissem o direito a língua materna indígena. Desse modo, falar sobre ensino de língua portuguesa como L2 em contexto indígena, além de complexo, implica em vários questionamentos, tais como: Como ensinar o português L2 valorizando as línguas indígenas? Como estimular a comunidade indígena a não abandonar sua língua materna? Como são tratadas as diferenças e as interferências linguísticas pelos professores de línguas nas comunidades? Quais concepções de língua têm os 
professores que ensinam línguas, bem como os professores formadores? Quais os preconceitos linguísticos da comunidade? É possível superá-los?

Relatos de professores indígenas apontam para o despreparo dos professores tanto indígenas quanto não indígenas ao lidar com um contexto particular como o das comunidades indígenas.

Em algumas escolas da região, as crianças chegam à escola falando apenas a língua materna, isso exige que o professor seja bilíngue, que compreenda os processos cognitivos implicados no processo de escolarização de uma nova língua. Em outros casos, os alunos são bilíngues. Segundo Amaral (2011), é preciso compreender que os bilíngues têm necessidades diferenciadas em termos educacionais, ou seja, devem-se entender os processos de aquisição de cada uma das línguas por eles faladas. Em citação a Grosjean (2008), Amaral traz uma reconceitualização do termo bilíngue, que tem como norte o uso em diferentes situações comunicativas:

O bilíngue passa a ser alguém que usa mais de uma língua para atingir objetivos comunicativos em diferentes contextos sociolinguísticos. Essa reconceitualização traz novos desafios para os estudos do bilinguismo ao incluir dentro da categoria de bilíngue qualquer falante com competência comunicativa em mais de uma língua, independente de seu grau de fluência ou correção gramatical (AMARAL, 2011, p. 16).

Segundo o autor, o educador que trabalha com bilíngue tem que diferenciar dificuldades linguísticas do uso de alternância do código para conseguir seus objetivos comunicativos na interação. Contudo, essa dificuldade em lidar com as situações linguísticas, em contexto multilíngue, gera situações como as apontadas por Ramos (2002) em uma escola indígena da região de Dourados, em que um professor não indígena relata um problema quanto ao aprendizado do português:

um aluno, ele repetiu já dois anos por motivo da língua dele [Guarani] foi difícil trabalhar com ele (...) esse ano ele reprovou de novo, não conseguiu passar (...) ele está com (09) nove anos de idade na primeira série, esse já é o terceiro ano que ele reprova na primeira série (...) ele tem dificuldade de entender o que a gente fala... (comunicação pessoal) grifo nosso). ${ }^{5}$

Nesse relato, pode-se perceber que os professores de língua estão despreparados para o ensino em contexto bilíngue. A reprovação ainda é a prática mais comum nas escolas da região. Dizer que o aluno não sabe o português geralmente serve de mote para reprovação também em outras disciplinas. Não há um olhar diferenciado ou sensibilizado para a questão

\footnotetext{
5 Informação verbal sobre fala de professor indígena em Ramos (2002).
} 
da língua tanto nas escolas indígenas, visto que os professores indígenas também foram formados sob as mesmas perspectivas dos professores não indígenas, quanto no próprio ensino de língua. Ou seja, aprender língua é praticamente estudar apenas nomenclatura da língua, é dominar as terminologias gramaticais. A língua em uso não é foco de muitos professores que carregam ainda todo o seu preconceito com quem fala ou escreve diferente da norma estabelecida como a língua.

Assim, as marcas gramaticais são taxadas como erros simplesmente, e os sujeitos como inferiores (e com dificuldades de aprendizagem), ou seja, não é apenas a capacidade linguística, mas o sujeito em si é tido como menor, sua capacidade cognitiva é posta à prova.

Vejamos alguns exemplos ${ }^{6}$ de textos de alunos de $2^{\circ}$ ano do Ensino Fundamental e as dificuldades que enfrentam para escrever em língua portuguesa:

Branca de neve (texto III)

Branca de neve ele en cotro corruga ele levou na casa dele comeu de pois domi branca de neve marava com pai dele pois pai dele morreu de pois ele mora na casa de madrata.

Branca de neve (texto IV)

Era uma vez um minina que tão bonito atem ela entrou um pricipi ficarum felize e cicazaram

Branca de neve (texto V)

Era um branca de neve que era mais bonita de todos gostava dele é um dia a padrasta ficou invejozo é falou para o espelho queí é mais bela de todos é você dis o espelho ea padrasta dela comesou a pular e falou di novo [sic] (RAMOS, 2002, p. 40 (grifos da autora).

Esses trechos de textos mostram as dificuldades enfrentadas por crianças que possuem a língua indígena como língua materna. Nos trechos acima, há muitas trocas com relação aos definidores de gênero masculino e feminino. São trocas que dificilmente aconteceriam com um falante da língua portuguesa, mesmo que ainda não tenha sido alfabetizado. Essas "trocas", são decorrentes de interferências da língua materna durante a aquisição da segunda língua. Contudo, são tidas como sérios erros gramaticais ou ortográficos, logo, muitos professores entendem que essas crianças que não sabem o português não poderiam passar de ano.

\footnotetext{
${ }^{6}$ Estes exemplos estão em Ramos (2002) no trabalho intitulado: O Ensino de da Língua Portuguesa na Escola Tengatuí Marangatu de Dourados.
} 
Ramos (2002), em citação a Pablo Scott (1981), faz algumas considerações sobre a língua guarani:

I.Em guarani existe apenas uma partícula para pluralizar os substantivos e adjetivos (kuéra), e não se flexiona em gêneros, serve tanto para masculino, quanto para feminino, pois em guarani não existe desinência para masculino e feminino e nem concordância entre substantivo e adjetivos.

Portanto, construções como "o menina”; "um branca”, entre outras mostra a estrutura gramatical de outra língua que deveria ser analisada e respeitada.

II. A sintaxe do guarani segue estrutura diferente do português:

a) a parte regida antepõe-se à regente, assim: po= mãos e pe=com em guarani se escreve "mãos com" ao contrário do português "com as mãos";

b) o específico pospõe-se ao genérico, assim: yvyra=árvore e rapo=raiz em guarani se escreve "árvore raiz" e em português "raiz da árvore".

c) o determinado vem antes do determinante, assim: hi ári=ele em cima, em português seria "em cima dele".

Essas observações servem para mostrar o quanto a falta de conhecimento e preconceito em relação ao outro, à sua cultura e à sua língua o posicionam num lugar menor. $\mathrm{O}$ conhecimento pode libertar ou aprisionar, tudo depende das escolhas que fazemos. Desse modo, a língua está envolta em assimetrias de poder. Hamel (2013) diz que as políticas de planejamento linguístico devem intervir na verticalidade das línguas e na sua assimetria (HAMEL, 2013, p. 40).

Sabemos que, enquanto a língua indígena ocupar um espaço menor, não haverá possibilidade de mudança. Visibilizar essa língua é um primeiro passo para mudar concepções preconceituosas. Essa visibilização pode ser feita em sala de aula, a partir do conhecimento da sua estrutura e do reconhecimento pelos professores de que as diferenças linguísticas não implicam em ser melhores ou piores.

\section{PRÁTICAS LÍNGUÍSTICAS EM SALA DE AULA}

Foram observadas no total $50 \mathrm{~h} / \mathrm{a}$, com exceção dos dias em que foram dedicados a outras atividades da escola. As turmas escolhidas foram as do Ensino Fundamental II, tendo em vista que nessas turmas o público é heterogêneo, falam Língua Portuguesa e Língua Indígena.

A primeira aula em uma das turmas consistiria na aplicação de uma prova sobre substantivos. Enquanto realizavam a prova, perguntavam o tempo todo sobre o que estava 
escrito nas provas, pois não compreendiam algumas palavras. A prova foi manuscrita pelo professor e depois xerocopiada.

Observamos que os alunos não compreenderam o sentido de substantivo, visto que estes substantivos foram trabalhados de forma descontextualizada. Alguns exemplos de substantivos: colmeia, alcateia, álbum, enxoval, enxame, dentre outros. Havia confusão, e eles procuravam estabelecer uma ligação com algo que conhecem:
A: O que é colmeia?
A: Professor, Zé Colmeia?
P: Então colmeia veio de Zé? (risos)
P: Água? Será que colmeia nomeia água?

Pode-se observar que a forma como foi trabalhado o ensino de substantivos é a mesma ainda de muitas escolas convencionais, ou seja, lista de palavras descontextualizadas. Esse método provavelmente não ajuda na compreensão ou fixação dos conteúdos estudados, visto que não produz sentido de forma isolada e só aquilo que faz sentido para nós é melhor assimilado. Assim, pudemos observar olhares distantes que procuravam em algum lugar entender o que se pedia na prova.

Os alunos também deveriam escrever um texto sobre inclusão, contudo alguns não sabiam como escrever o texto sobre inclusão, perguntando-se: “o que é inclusão?"

Observa-se que a escola indígena mantém o padrão das escolas não indígenas no que se refere ao ensino de língua portuguesa, ou seja, ênfase no ensino de gramática e de forma descontextualizada. A língua é vista como fragmentada, podendo ser analisada em partes. Sabemos que esta análise é possível, mas focar a análise na nomenclatura da língua não significa ensinar a língua, apenas iniciar um estudo acerca da estrutura da língua. Contudo, este tem sido o modelo de ensino em muitas escolas fora da aldeia e dentro dela. Conforme Antunes (2003), as atividades em torno da gramática têm sido realizadas de forma descontextualizada e desvinculada dos usos reais da língua, frases são feitas para virarem exercícios. Segundo a autora, a gramática tem dado,

primazia em questões sem importância para a competência comunicativa dos falantes. A este propósito, valia a pena perguntar-se qual a competência comunicativa que há em distinguir um adjunto adnominal de um complemento nominal, ou ainda, em reconhecer as diferentes funções do QUE ou do SE, coisas com as quais muito tempo de aula ainda é desperdiçado (ANTUNES, 2003, p.31). 
Essa fixação pela nomenclatura da língua vem da crença de que saber nomear uma classe gramatical permite ao falante ou escritor expressar-se "corretamente" na língua. Vários estudos provam que o conhecimento de estruturas gramaticais não garante o desenvolvimento das principais competências linguísticas, visto que é possível se comunicar oralmente, por exemplo, sem analisar se estamos utilizando um adjetivo ou substantivo. A língua é fluida e não se prende a termos pré-determinados. Antunes (2003) assinala para o fato de que esse reducionismo da língua afasta uma compreensão mais relevante da linguagem, ou seja, o objetivo da linguagem é a interação social. Portanto, a competência principal é a comunicação sob todas as formas, seja oral ou escrita. A autora aponta que os PCNs estabelecem que

os "conteúdos de língua portuguesa devem se articular em torno de dois grandes eixos: o do uso da língua oral e escrita e o da reflexão acerca desses usos. Nenhuma atenção é concedida aos conteúdos gramaticais, na forma e na sequência tradicional das classes de palavras, tal como aparecia nos programas de ensino antes (ANTUNES, p. 22, 2003). (Grifos da autora)

Seria muito mais interessante pensar em como utilizar a língua em determinados contextos sociais e exercitar isso de uma forma menos metódica e presa a aspectos gramaticais. A forma como as atividades gramaticais são ensinadas e cobradas nas avaliações não garantem o aprendizado eficaz na comunicação, conforme constatamos nas observações a seguir.

As atividades parecem obedecer a essa sequência, ou seja, a mesma do livro didático, que normalmente apresenta um texto "motivador", questões de interpretação, pontos gramaticais e algum vocabulário.

Durante as observações em sala não houve um trabalho contextualizado em relação aos aspectos gramaticais. Ou seja, as crianças leem as questões, respondem e algumas levam para o professor olhar, este verifica as corretas e devolve aos alunos. Não houve uma correção em conjunto com a turma.

Antunes (2003) chama atenção para o fato de que na escola ainda há um processo de aquisição da escrita que ignora o sujeito aprendiz na testagem de suas hipóteses de representação gráfica da língua, além de uma prática de escrita improvisada, sem planejamento ou revisão. Segundo a autora:

é na escola que as pessoas "exercitam" a linguagem ao contrário, ou seja, a linguagem que não diz nada. Nessa linguagem vazia, os princípios básicos da textualidade são violados, porque o que se diz é reduzido a uma sequência de frases desligadas umas das 
outras, sem qualquer perspectiva a escrita de ordem ou de progressão e sem responder a qualquer tipo particular de contexto social (ANTUNES, 2013, p. 26).

Os alunos precisam saber qual a intenção, qual o objetivo ao escrever, para quem escrever, pois isso irá direcionar suas escolhas lexicais, seus argumentos e posicionamentos em relação ao assunto tratado. A prática de escrita deve fazer sentido para quem escreve de modo que consiga estabelecer uma relação dialógica com o espaço sócio-histórico e cultural.

A escrita está primariamente relacionada com as práticas de leitura, pois envolvem processos múltiplos no ato de compreender, assim, Kleiman (2002), aponta alguns fatos interessantes sobre o ato de leitura. A leitura envolve conhecimento prévio, objetivos de leitura e compreensão. A leitura é considerada um processo interativo, pois envolve diversos níveis de conhecimento tais como o linguístico, o textual e o conhecimento de mundo e que, dessa forma, estão interligados.

Kleiman (2002) destaca a importância do conhecimento linguístico que envolve o conhecimento de como pronunciar, conhecer o vocabulário e regras da língua e conhecimento sobre o uso da língua. Antunes (2003) diz que a prática de leitura em sala de aula, geralmente, é desvinculada dos usos sociais:

Uma atividade de leitura centrada nas habilidades mecânicas de decodificação da escrita, sem dirigir, contudo, a aquisição de tais habilidades para a dimensão da interação verbal - quase sempre, nessas circunstâncias, não há leitura, porque não há "encontro" com ninguém do outro lado do texto (ANTUNES, 2003, p. 27).

Nas observações em sala, pudemos perceber falta de planejamento em relação ao ato de ler em sala, tais como objetivos voltados para o desenvolvimento da leitura num contexto social. Pensando a leitura como prática social, que vai além de decodificações da língua, que envolve um diálogo com o autor, com as situações apontadas, enfim, uma leitura de mundo. Nas práticas de leitura escolares presenciadas não encontramos esses aspectos como mostra os trechos abaixo.

Trecho: Os alunos ${ }^{7}$ são postos em círculo para fazer a leitura de um texto sobre artigo de opinião:
A: (leitura ininteligível)
P: Isso. Próximo
A: É nesse cenário? (risos leitura em voz baixa)
P: Próximo.

\footnotetext{
${ }^{7}$ Informação verbal colhida em sala de aula.
} 
A: (Lê baixo. Conversas barulho).

P: Você parou onde? Pode ler até ...

(alguns conversam, riem)

P: Você conseguiu escutar onde ele parou? Onde você parou Tom?

P: Continua então, "em vez de pensar em novas leis"...

A: (leitura ininteligível)

Após a leitura, o professor pergunta se os alunos entenderam o texto e diz que trouxe algumas perguntas para responderem, pois os alunos precisam de mais informações. A seguir, dita dez perguntas sobre o texto copiado anteriormente para os alunos responderem. Contudo, apesar de algumas perguntas serem interessantes, não houve uma conversa sobre elas, os alunos responderam sozinhos. Geraldi (2002) faz alguns apontamentos sobre os livros didáticos, segundo o autor:

Observando textos colocados à disposição dos estudantes por grande parte dos livros didáticos de "comunicação e expressão", pode-se constatar que tais textos não respondem a qualquer "para que". Consequentemente, o único "para que lê-lo" que o estudante descobre de imediato é responder às questões formuladas a título de interpretação: eis a simulação da leitura (GERALDI, 2002, p. 93).

A leitura deve mobilizar a pessoa para um posicionamento crítico, de modo que isso produza ação. Leitura apenas para responder questões superficiais sem discussão, sem desvendar a intencionalidade de quem escreve não desenvolve competências para análise crítica dos fatos. Nessa situação, os alunos não estão preparados para as tais provas do governo. Presenciamos esse fato quando, em uma das aulas, os alunos tiveram que responder a um simulado da Secretaria Municipal de Educação. Quando indagado sobre o simulado, o professor disse não ter recebido qualquer informação ou orientação sobre o motivo do simulado, apenas aplicou-o. Durante a realização, os alunos ${ }^{8}$ liam em voz alta demonstrando suas dúvidas:

A: Não consigo ler nada.

A: O que é argumento, professor?

P: O que que eles falam.

A: O que é contradição, professor?

O simulado apresentado era todo de leitura e interpretação de textos, alguns termos eram desconhecidos dos alunos, algumas questões de interpretação estavam na superfície do texto, outras eram complexas, ou seja, envolviam habilidades de inferência e leitura de

\footnotetext{
${ }^{8}$ Informação verbal colhida durante aulas.
} 
mundo, ou melhor dizendo, leitura de mundo não indígena, além de conhecimento de sentido conotativo da linguagem.

Sabemos que a prática de leitura em sala de aula deve preparar os alunos para situações reais de uso da língua. Contudo, o que vemos é uma centralização nos aspectos gramaticais isolados das práticas sócio-discurvas.

\section{AS EXPECTATIVAS DOS ALUNOS INDÍGENAS: AS ENTRELINHAS ENTRE O QUE SE TEM E O QUE SE ALMEJA EM TERMOS DE LÍNGUA NA ALDEIA.}

Para verificar como os alunos pensavam em relação à sua língua e à língua portuguesa, foi-lhes pedido que respondessem sobre a importância da língua para eles, sua família e para a sua comunidade. Além dos alunos, foram entrevistados o coordenador pedagógico e alguns professores indígenas da escola. Sabemos que a língua(gem) como fator social produz imagens e ideologias, é principalmente no campo da linguagem que as concepções e valores sociais são expressos. Considerando as relações estabelecidas entre linguagem e poder, fazemos alguns apontamentos de uma perspectiva sócio discursiva do que se pensa na aldeia quanto à língua indígena e seus usos.

Observamos nas falas dos alunos um discurso que começa a tomar um novo caminho para a produção de mudanças sociais. Para Fairclough (2008), a linguagem está no centro das mudanças sociais, pois incluem mudanças nas práticas de linguagem e/ou discursivas:

Muitas dessas mudanças sociais não envolvem apenas a linguagem, mas são constituídas de modo significativo por mudanças nas práticas de linguagem; e talvez seja uma indicação da importância crescente da linguagem na mudança social e cultural que tentativas de definir a direção da mudança cada vez mais incluam tentativas de mudar as práticas de linguagem (FAIRCLOUGH, 2008, p. 24-25).

Desse modo, observamos que o discurso das crianças indígenas em relação à língua indígena é resultado das novas práticas discursivas impulsionadas por muitos movimentos sociais a favor da preservação da língua indígena. Sendo assim, a língua indígena para eles traz um sentimento de identidade, lugar seguro e de identificação de significação, tradição:

Na minha comunidade todos fala a minha língua guarani.

Eu fala em Kaiowá com meu pai com minha mae i todos o meu parenti.

importante em nossa linguagem é o Guarany.

Quando eu nasci minha família já falava em guarani. ${ }^{9}$

(grifos nossos).

\footnotetext{
${ }^{9}$ Informação verbal coletada em questionário.
} 
Assim, como aponta Cavalcanti (2006), "um indivíduo emerge através dos processos de interação social não como produto final, mas como alguém que é (re)constituído através das várias práticas discursivas das quais participa” (CAVALCANTI, 2006, P. 242). Essas práticas discursivas vão construindo novos posicionamentos em relação ao que se deseja como ideal para a comunidade.

Outro fator apontado nas falas dos alunos é a preocupação com a perda da língua para o povo indígena. As crianças começam a pensar na língua como fator de fortalecimento de sua cultura e seus valores:

É muito importante fala guarani pra gente não esquese nossa língua.

Acontece qui os indígenas estão abandonando a língua, mas pra mim e muito importante de falar uma língua tão diferente, muitos estão também valorizando a língua tomara que daqui um dia os indígenas irão abrir o seu olhos para valorizar as cultura, principalmente de língua, porque é muito importante.

Minha família fala mais prami em guarani se agente perde a costume si agente falar em português agente não vai sabe a nossa própria língua.

Prami e importância que todos fala ligua guarani so que tem alguém que nem liga para a sua lingue so espero que eles não amodone a sua língua. ${ }^{10}$ (grifos nossos).

Percebe-se que o fator valorização da língua para essa comunidade é muito importante. O mais interessante é ver as crianças elaborando essa preocupação com a língua, pois, sem dúvida, elas podem ajudar (e muito) a fixar essa cultura de preservação da língua de seu povo.

Apesar do interesse dos alunos registrado em suas falas, e dos resultados dos usos linguísticos apontarem para a presença forte da língua indígena na comunidade, a escola, aparentemente, não se apresenta como um local que incentive ou valorize a língua indígena escrita. Na proposta de uma escola indígena bilíngue seria interessante que essa língua fosse representada nos espaços, ou que pelo menos estivesse representada juntamente com o português, porém, na escola analisada, não observamos a língua indígena representada graficamente nos espaços como murais por exemplo, embora haja representação escrita dessa língua.

\footnotetext{
${ }^{10}$ Essas falas foram coletadas por meio de questionário.
} 
Pelo fato de a maioria dos professores não ser falante da língua, isso altera o modo como a língua é vista e/ou ensinada, pois não sendo utilizada como língua de instrução, os alunos vão aos poucos perdendo o contato com a língua indígena.

A escrita da língua indígena na escola contribui para a valorização da língua, e para que ampliem suas competências no uso da mesma, conforme destaca o RCNEI (BRASIL, 1998, p. 120), "o fato de terem suas línguas tradicionais publicadas, descritas e documentadas - assim como acontece com as línguas de prestígio no mundo inteiro - tem sido motivo de orgulho e satisfação para muitos povos indígenas”.

Vemos como problemática a ausência da língua indígena no espaço escolar frente à imponente presença da língua portuguesa tanto nos livros didáticos quanto na maioria de professores que só falam em português na escola.

Durante as observações, percebemos que há por parte de alguns professores grande interesse em fazer uma escola diferenciada que tenha "cara de escola indígena", contudo percebe-se que falta saber "como fazer".

A escola indígena tem procurado ter cara de escola indígena (...) depois de anos sem pensar nas especificidades ainda não está efetivada, por que não está claro o que escola bilíngue... falta entendimento dos professores, entendimento do que é essa escola. (...) falta implementar currículo, calendário festivos (plantios, semana dos povos indígenas, falta professor ser falante da língua, falta parte pedagógica, conversar com os pais" (informação verbal extraída de fala de professor).

Quanto à língua, o coordenador da escola diz que a língua indígena "é instrumento de defesa e de identidade", pois, segundo ele, os mais velhos dizem que "o indígena que é falante da língua tem credibilidade".

\section{O ENSINO DE LÍNGUA PORTUGUESA COMO SEGUNDA LÍNGUA: O QUE DIZ O RCNEI (1998)}

O Referencial Curricular Nacional para as Escolas Indígenas (RCNE/Indígena) estabelece as orientações para uma escola específica, diferenciada e de qualidade. Desse modo, segundo o Referencial, "Este documento foi escrito na expectativa de que possa contribuir para diminuir a distância entre o discurso legal e as ações efetivamente postas em prática nas salas de aula das escolas indígenas" (BRASIL, 1998, p. 11).

Nesse sentido, afirma a necessidade de avaliação e reavaliação contínua da atuação pedagógica na escola: 
Para que essas tarefas possam ser levadas a cabo, é preciso um ambiente plural e intenso de discussão e reflexão sobre os significados embutidos na expressão "uma escola indígena especifica, diferenciada e de qualidade", de modo que tal expressão seja utilizada, não como um mero jargão da área, mas, sim, para descrever quais devem ser, de fato, seus reais atributos. O RCNE/Indígena pretende servir como um instrumento auxiliar nesta discussão e reflexão, já que ele se propõe a: a) explicitar os marcos comuns que distinguem escolas indígenas de escolas não-indígenas, b) refletir as novas intenções educativas que devem orientar as políticas públicas educacionais para as escolas indígenas brasileiras, c) apresentar os princípios mínimos necessários, em cada área de estudo do currículo, para que se possam traduzir os objetivos que se quer alcançar em procedimentos de sala de aula (BRASIL, 1998, p. 13, grifos nossos).

Pode-se perceber que as propostas do Referencial são bem claras quanto à autonomia dos professores e corpo escolar para tomada de decisões na escola. Contudo, não vemos essa proposta clara no contexto analisado. Os professores sentem-se inseguros em propor algo que para eles mesmos parece ir contra um modelo de escola o qual já estão acostumados ou condicionados.

Também é fato que, mesmo sendo uma escola indígena com $80 \%$ dos seus professores sendo indígenas, estes professores passaram pelo mesmo modelo educacional que agora precisam repensar e recriar. Isso provoca um desajustamento em muitos sentidos, ou seja, devem repensar crenças sobre a educação e os modelos de ensino baseados na imposição do poder, do saber hegemônico sobre o outro. Nas observações do conselho de classe, pudemos perceber em suas falas como estão presos ao modelo educacional que lhes foi imposto durante anos. Quando crianças, o modelo educacional que receberam foi o não indígena e o mesmo ocorreu em sua formação como profissionais docentes, ou seja, o modelo que possuem de educação escolar é o modelo de educação não indígena.

O ensino de português pautado nas regras gramaticais e não em um ensino real da língua é um dos modelos encucados na mente das pessoas, assim, sabe falar bem e escrever bem quem sabe regras gramaticais. Esse modelo foge inclusive dos próprios documentos para educação escolar não indígena. Segundo os Parâmetros Curriculares Nacionais: Língua Portuguesa (PCNS),

o domínio da língua tem estreita relação com a possibilidade de plena participação social, pois é por meio dela que o homem se comunica, tem acesso à informação, expressa e defende pontos de vista, partilha ou constrói visões de mundo, produz conhecimento (BRASIL, 1997, p. 15). 
Desse modo, a língua é considerada como algo vivo, em movimento, e que acompanha as mudanças sócio-culturais. De modo semelhante, o Referencial para Educação Indígena aponta que:

O homem usa a linguagem para expressar seus pensamentos, suas emoções e sentimentos, seus sonhos, seus desejos e intenções; pode usá-la para convencer e para construir discursos políticos; para fazer poesias, descrições, fatos. (...) A linguagem é, quase sempre, o meio mais importante através do qual os povos constroem, modificam e transmitem suas culturas. É por meio do uso da linguagem que a maneira de viver de uma sociedade é expressa e passa, constantemente reavaliada, de uma geração para outra. Os modos específicos de usar a linguagem são, por isso, como documentos de identidade de um povo num determinado momento de sua história (BRASIL, 1998, p. 113, Grifo nosso.)

Embora esses professores tenham tido uma educação escolar pautada no modelo de educação escolar não indígena, o RCNEI aponta muitos caminhos para o ensino de línguas na escola indígena. A língua para estar viva precisa ser utilizada, ter função dentro da comunidade. E para que isso ocorra, essa língua tem que ter representação oral e/ou escrita nas mais variadas situações. O questionário aplicado sobre os usos linguísticos mostrou que os alunos falam mais na língua indígena com sua família ao passo que quando vão para a escola, começam a utilizar mais a língua portuguesa, ou seja, aos poucos pode estar havendo um deslocamento linguístico. Segundo o Referencial:

se a comunidade tiver claro que cada língua tem o seu território, o seu domínio, e se ela mantiver cada língua em seu lugar específico, então a tendência é que seus membros permaneçam bilíngues. O problema, no entanto, é que devido à pressão social contra o uso das línguas indígenas, seus falantes passam a utilizar a língua portuguesa em ambientes que tradicionalmente não lhe pertencem (BRASIL, 1998, p. 118).

O ensino de português como segunda língua deveria ter um papel diferente do que atualmente tem na escola indígena. O RCNEI (BRASIL, 1998, p. 121) afirma a importância do português para as comunidades indígenas, pois "o conhecimento da língua portuguesa permite que as populações indígenas conheçam o funcionamento da sociedade envolvente e, ainda, que elas tenham acesso a informações e tecnologias variadas". Contudo, o modo como é ensinada difere em muito do que é proposto no Referencial.

O foco que se dá à língua portuguesa na atualidade não habilita ninguém a ter autonomia linguística, pois o ensino é pautado pelas regras gramaticais normativas e pelo estudo de sua nomenclatura, trabalho puramente taxonômico. A língua real da comunicação, das nuances produzidas pelo discurso não é ensinada em muitas escolas. Como adquirir fortalecimento político usando a língua portuguesa se o indígena não perceber o que anda por 
trás de determinados discursos, se não captar as artimanhas linguísticas que manipulam o poder e que delimita seu espaço sociocultural? A língua(gem) é mais que um amontoado de signos, ela permite uma conexão com o mundo, com a história social e política de um povo. Desse modo, estudar língua portuguesa na comunidade indígena deveria ir além das aulas de gramática e decorebas de nomenclatura.

O Referencial Curricular para Educação Indígena orienta que, se na comunidade o que predomina é o aluno chegar à escola sabendo apenas a língua indígena, e este é o caso da comunidade indígena em questão, a língua portuguesa deveria ser introduzida como segunda língua. Contudo, não é isso o que acontece. O português na escola ocupa uma carga horária extensa, e tal qual no ensino escolar tradicional, os alunos vão "aprendendo" o uso padrão da língua, e aspectos gramaticais. Conforme o Referencial:

é papel da escola ampliar as formas de expressão oral do aluno em língua portuguesa, para que ele possa se comunicar em novas situações (...) por esse motivo, não basta a escola ter como objetivo simplesmente alfabetizar seus alunos: ela tem o dever de criar condições para que eles aprendam a escrever textos adequados às suas intenções e aos contextos em que serão lidos e utilizados (BRASIL, 1998, p. 124; 126).

Desse modo, o RCNEI (BRASIL, 1998, p.126) afirma que o aprendizado da escrita em português para os povos indígenas tem funções bem definidas, ou seja, criar as condições necessárias para que aprendam escrever textos adequados a suas intenções e contextos sociais. Em muitos relatos de povos indígenas está a necessidade de aprender o português como forma de defesa.

Outro fator importante apontado pelo Referencial é que a melhor forma de inserir o português para os alunos indígenas seria depois de já terem sido alfabetizados na língua indígena. Esse fato é apontado em Merril Swain (1986), como o princípio das coisas primeiras, ou seja, segundo a autora a criança deve aprender primeiro sua língua materna, pois a língua faz parte de sua identidade, da sua cultura e da comunidade.

A aceitação da língua materna em casa e na escola é claramente, então, um dos primeiros passos para criar um ambiente onde o aprendizado possa ocorrer e um ambiente que favoreça sentimentos de auto-estima e auto-confiança. Mas, a aceitação da língua materna é apenas o começo. Encorajamento ativo (incentivo) para utilizar a língua materna na escola é igualmente importante. Isso pode ser feito de variadas formas. Um modo, naturalmente, é usar a língua como um meio de instrução, que não apenas melhore a compreensão dos alunos, com a consequente melhora do desempenho escolar, mas também forneça evidência concreta de que a língua materna é útil e um instrumento valorizado (...) o que quer que possa ser feito para envolver a família e a comunidade no programa escolar ajudará a convencer os alunos de que a escola é sincera no seu respeito para com sua língua e sua cultura (SWAIN, 1986, p. 3). 
Esse encorajamento nessa escola indígena ainda não está bem resolvido, pois a língua de instrução majoritária na escola é a língua portuguesa. O RCNEI aponta, sobretudo para o professor indígena como o agente principal do que e como será ensinado aos seus alunos, já que ele conhece os costumes e a necessidade de seus alunos, deverá perguntar-se sempre se:

as informações e sugestões aqui contidas podem ser úteis para o desenvolvimento cultural e político do meu povo? Elas podem ser úteis para o meu trabalho pedagógico? E possível adaptar estas sugestões à minha escola e ao meu modo de trabalhar? Em que língua faz sentido trabalhar essa atividade, na primeira ou na segunda língua dos meus alunos? Em língua indígena ou em português? (BRASIL, 1998, p. 131).

Assim, há muitas sugestões para o trabalho com segunda língua, como dramatizações de diálogos curtos, ou seja, primeiro valoriza-se a oralidade em situações de uso social da língua portuguesa, por exemplo. Atividades com música, jogos, brincadeiras também são sugeridas pelo Referencial.

O foco do trabalho com a segunda língua deve estar centrado nas necessidades de uso da comunidade. Assim, as atividades de leitura e escrita devem tornar o processo de aprendizagem significativo para o aluno. Então, é importante que a leitura e escrita tenha função social e "para que a escrita faça sentido para os alunos, é preciso, portanto, que eles se envolvam em atividades onde a linguagem escrita apareça contextualizada e sirva para alguma coisa" (BRASIL, 1998, p. 135).

Há também sugestões para a escrita com crianças, explorando sua criatividade com os desenhos livres, de modo que ela possa representar o que fala por meio de imagens. Segundo o referencial, quando a criança desenha, ela está construindo seu mundo, aos poucos vão entendendo como representar as letras e palavras. Chama atenção para o fato de que o professor deve conversar sobre o significado do que está escrito, ou seja, apenas copiar do quadro, fazer separação silábica ou copiando sentenças sem sentido e descontextualizadas não ajuda o aluno a elaborar suas próprias ideias sobre a escrita.

Uma atividade interessante seria organizar uma correspondência por meio de cartas com alunos de escolas não indígenas. Seria uma oportunidade para a prática de uma escrita que faça sentido e, por outro lado, uma oportunidade para troca de conhecimentos e sensibilização para um olhar sobre a cultura e o saber do outro. Segundo o RCNEI,

um texto escrito só existe em função de quem o irá 1er e é por isso que é muito importante levar os alunos não apenas a imaginar quem serão os leitores dos textos que eles produzem, mas também e a ter sempre em mente esse perfil do leitor no momento do planejamento, da escrita, da revisão e da eventual reelaboração dos seus textos (BRASIL, 1998, p. 138). 
D’Angelis (2013) em Ensino de Português em Comunidade Indígenas ( $1^{\mathrm{a}}$ e $2^{\mathrm{a}}$ língua) traz experiências de vários pesquisadores com o ensino de português como segunda língua em comunidades indígenas. Assim, Borges (2013) argumenta que é necessário ressignificar a compreensão do ensino de LP2 para as necessidades dos povos indígenas. Em seu trabalho com segunda língua em contexto indígena, a pesquisadora estabeleceu alguns objetivos que deveriam ser considerados no ensino de LP2, tais como: refletir sobre como o processo de leitura e escrita não está desvinculado da prática social e refletir sobre a importância dos vários tipos de textos que regulamentam a vida.

Ferreira (2013) diz que "mais do que falante ou escrevente, o aluno é um sujeito que interpreta e tem uma posição na sociedade, na família e na escola" (Ferreira, 2013, p. 28). A autora afirma que o ensino de português como segunda língua em comunidades indígenas deve levar em consideração, principalmente, o enfoque que essas comunidades querem dar aos aspectos sociais que se relacionam com as questões linguísticas.

De modo geral, as orientações do RCNEI, bem como as pesquisas com português como segunda língua, apontam que o ensino de LP2 deve focar em um ensino e aprendizagem que sejam significativos e que existem outras formas de abordar a língua que podem levar a um aprendizado contextualizado e, portanto, mais eficaz.

\section{CONSIDERAÇÕES FINAIS}

O direito a uma escola bilíngue e diferenciada assegurado, por meio de leis e documentos sobre educação escolar indígena, ainda encontra grandes desafios para que, de fato, seja concretizado na prática. A escola indígena ainda passa por um processo de reaprendizagem sobre educação escolar, visto que durante séculos foi-lhe imposto o modelo de educação escolar não indígena.

Sendo assim, percebemos que alguns professores indígenas no contexto analisado querem mudar ou ressignificar sua educação escolar, mas ainda estão presos ao modelo imposto, às formas de ensinar e, principalmente, a um sistema de educação que condiciona e dificulta a implantação de uma escola bilíngue e diferenciada por meio de gestores que não aceitam mudanças de paradigmas. 
A apropriação da língua portuguesa pelo indígena representa não apenas um direito, mas uma ferramenta necessária para a comunicação e para defesa de seus interesses. Contudo, a forma estão se apropriando dessa língua é um ponto a ser questionado, pois não estamos falando de apropriação do código linguístico do português, mas da língua no sentido em que dá suporte para entender os processos de socialização dos sujeitos, de dar autonomia para questionar e para se posicionar na busca de seus direitos ou expectativas.

A forma como a língua portuguesa está sendo abordada na escola não lhes garante um acesso linguístico de qualidade na sociedade envolvente. Desse modo, a língua portuguesa ensinada na escola indígena centrada em ensino gramatical, sem considerar as variantes linguísticas e a interferências do sujeito bilíngue, contribui para uma estigmatização do falante. Sabemos que esses posicionamentos em relação à língua não capacitam os estudantes para serem autônomos na escrita ou no aprendizado da língua, nem para uma comunicação eficiente nos diversos espaços sociais.

A análise dos dados mostrou que há um interesse por parte dos professores e por parte de alguns gestores em fazer uma escola diferenciada, mas falta saber como fazer. Ainda têm como referencial as diretrizes de uma educação escolar não indígena, apesar de terem certa autonomia para mudar, encontram muitos desafios pela frente. Um deles é o desafio metodológico e a falta de formação da maioria dos professores.

Observamos durante a pesquisa que o professor de português, embora seja indígena e falante da língua, está preso aos métodos de ensino de língua utilizados nas escolas não indígenas. Assim, as aulas são baseadas em ensino de gramática, cópias de textos e nomenclatura da língua, ou seja, a língua não é ensinada de modo significativo e contextualizado. O objetivo da linguagem é a interação social, segundo os PCNs, deve-se refletir sobre o uso da língua (BRASIL, 1997).

As práticas de leitura também são realizadas de modo mecânico, é uma leitura que não mobiliza o sujeito para o desenvolvimento de habilidades críticas e construtivas. São aulas centradas em responder questões superficiais. O português deveria ser ensinado como segunda língua, observando-se os interesses da comunidade de modo que fizesse sentido para os alunos.

A escola utiliza um livro didático que a rede de ensino municipal distribui, contudo, este livro não foi construído para o ensino linguístico de comunidades indígenas e, portanto, não é 
capaz de aprimorar suas habilidades comunicativas. Além do que, novamente, os alunos têm que copiar do livro todo o conteúdo proposto pelo professor.

Percebemos nas falas dos alunos que há um discurso forte em favorecimento e reconhecimento de sua língua. Acreditam que falar a língua indígena é importante para a manutenção de seus valores, pois sua língua constitui a herança de seus antepassados, assim, afirmaram, na sua maioria, o desejo de manter a língua e preocupação com o seu possível desaparecimento. Podemos perceber nas falas dos alunos uma esperança que deve ser mantida. Sendo assim, os professores da escola têm papel fundamental na alimentação dessa esperança. Nesse sentido, os professores de escolas indígenas precisam de formação específica, mais do que isso, precisam querer desconstruir as formas de aprendizagem que lhes foram impostas e reaprender um novo modo de aprender e ensinar na escola, um modo que resgate os princípios de ensino e aprendizagem que estão nas raízes de sua cultura e de seu saber.

Conforme nos apontou um dos gestores da escola, há um interesse em ter uma escola diferenciada, específica e bilíngue, contudo, segundo ele, "a escola indígena tem procurado ter cara de escola indígena (...) depois de anos sem pensar nas especificidades ainda não está efetivada, por que não está claro o que é escola bilíngue... falta entendimento dos professores, entendimento do que é essa escola".

Para que essa escola diferenciada aconteça, não apenas as formações são importantes, mas é preciso que haja a desconstrução dos discursos colonizadores que estão impregnados nos livros didáticos, nas estruturas do sistema escolar e na gestão, pois esses discursos foram incutidos e para desconstruí-los é preciso que novos discursos ocupem seu espaço e colaborem na construção de escola crítica.

Os professores indígenas não têm culpa de não saberem o que fazer com a educação escolar, pois nem mesmo a escola não indígena sabe o que fazer. A sociedade começa a perceber que a educação que temos, com os conteúdos que temos, não está promovendo um mundo melhor, onde seus cidadãos sejam engajados numa causa comum. Vivemos uma sociedade cada vez mais consumista e individualista, valores que as comunidades indígenas não têm como princípios de vida.

É preciso refletir, então, sobre quais são os valores que desejam que suas crianças apreendam, pois isso norteará a forma como o ensino de língua será ministrado. Se acreditarem que uns são menores por não se expressarem conforme determinado padrão de 
uma língua, então o ensino terá um foco. Se acreditarem que as pessoas são muito mais que os seus modos de falar, então, o ensino de língua na escola pode ser bem mais abrangente, ter uma perspectiva mais humanista e inclusiva.

Como já dissemos, não basta ser indígena e falar a língua do seu povo, é preciso que cada sujeito professor se comprometa em ter uma escola diferenciada em sua comunidade, mas antes, ele mesmo precisa perceber que a sujeição a qual os povos indígenas sofreram durante séculos, pois a imposição da educação escolar não indígena como a forma ideal de ensino e aprendizagem, condicionou o modo como os próprios professores aprendem e, consequentemente, isso interfere no modo como ensinam atualmente, como selecionam os conteúdos, como avaliam seus alunos, logo, é preciso criticar essas didáticas e contextualizálas.

\section{REFERÊNCIAS BIBLIOGRÁFICAS}

ALMEIDA FILHO, José Carlos Paes de. (2013). Dimensões Comunicativas no Ensino de Linguas. Campinas, SP: Pontes.

AMARAL, Luiz. (2011). "Bilinguismo, aquisição, letramento e o ensino de múltiplas línguas em escolas indígenas no Brasil”. In: Cadernos de Educação Escolar Indígena - Faculdade Intercultural. JANUÁRIO, E. \& SILVA, F. S. (Org.). Cáceres. UNEMAT, v. 9, n. 1.

ANTUNES, Irandé. (2003). Aula de Português: encontro e interação. São Paulo: Parábola Editorial.

BRASIL. Ministério da Educação (1996). Parâmetros curriculares nacionais: língua portuguesa / Secretaria de Educação Fundamental. - Brasília.

BRASIL. Ministério da Educação (1998). RCNEI - Referencial Curricular Nacional para as Escolas Indígenas. Brasília: MEC/SEF.

BRASIL. Câmara de Educação Básica (1999). RESOLUÇÃO CEB $N^{o} 3$, de 10 de Novembro de 1999.

BORGES, Agueda Aparecida da Cruz. (2013). "Língua Portuguesa para índios Munduruku: desafios e possibilidades de ensino”. In: D’ANGELIS, W. R. (Org.) Ensino de Português em comunidades indígenas: ( $1^{\mathrm{a}}$ e $2^{\mathrm{a}}$ língua). Campinas, SP: Curt Nimuendajú.

BRUNO, Lúcia. (2011). "Gestão da educação escolar indígena diferenciada: contradições, limites e possibilidades”. Revista Brasileira de Estudos Pedagógicos, Brasília, v. 92, n. 232, p. 639-662, set./dez. 
CAVALCANTI, Marilda Cavalcanti. (2006). "Um olhar metateórico e metametodológico em pesquisa em linguística aplicada”. In: Por uma Lingüística Aplicada Indisciplinar. (Org.) Luiz Paulo da Moita Lopez. Parábola Editora.

D'ANGELIS, Wilmar. (2012). Aprisionando sonhos: a educação escolar indígena no Brasil. Campinas, SP: Curt Nimuendajú, p. 01-70.

D’ANGELIS, Wilmar. (Org.). (2013). Ensino de Português em comunidades indígenas: $\left(1^{a} e\right.$ $2^{a}$ língua). Campinas, SP: Curt Nimuendajú, 2013.

FAIRCLOUGH, Norman. (2008). Discurso e Mudança Social. Brasília. Editora Universidade de Brasília.

FERREIRA, Luisa Lucimar. (2013). "Produção de Jornal nas aulas de Português $2^{a}$ língua (Projeto Ibaorebu - Munduruku)”. In: D’ANGELIS, W. R. (Org.) Ensino de Português em comunidades indígenas: $\left(1^{a}\right.$ e $2^{a}$ língua $)$. Campinas, SP: Curt Nimuendajú.

GERALDI, João Wanderley. (2002). "Prática da Leitura na Escola". In: O texto na sala de aula. (Org.) João Wanderley Geraldi. Ática.

HAMEL, R. E. (2013). "Relaciones entre lenguas y políticas linguísticas en la globalización”. In: SBERRO, S.; HARPELLER, R. N. (eds). Lengua y Poder. Un régimen lingüístico para américa del norte. Thundes Bay: Lakehead University Centre for Northen Studies, p. 28-53.

KLEIMAN, Angela. (2002). Texto e Leitor: Aspectos Cognitivos da Leitura. Campinas, SP: Pontes.

MAHER. T. M. (1994). “O Ensino de Língua Portuguesa nas Escolas Indígenas”. Em Aberto, Brasília, ano 14, n.63, jul./set.

MAHER, T. M. (2010). "Políticas Linguísticas e Políticas de Identidade: currículo e representações de professores indígenas na Amazônia ocidental brasileira”. Currículo sem Fronteiras, v.10, n.1, pp.33-48, Jan/Jun.

MELlo, L. e ROJAS, J. (2012). Educação, Pesquisa e Prática Docente em Diferentes Contextos. Campo Grande/MS, Life Editora.

MONSERRAT, R. M. F. (2006). "Planejamento Linguístico nas Sociedades Indígenas do Brasil Hoje: O Espaço e o Futuro das Línguas Indígenas". In: GRUPIONI, D. B. (Org.). Formação de Professores Indígenas: repensando trajetórias. Brasília. MEC/Secretaria de Educação Continuada, Alfabetização e Diversidade.

PEREIRA, M. C. (2013). Desafios de Ensinar Português em Cenário Indígena - O caso de Mato Grosso do Sul. In: SILVA, Kleber Aparecido da/SANTOS, Danúsia Torres dos (Orgs). Português como Língua (Inter) Nacional: Faces e Interfaces. Campinas, SP: Pontes. 
RAMOS, M. A. S. (2002). O Ensino de Língua Portuguesa na Escola Tengatuí Marangatu de Dourados. Monografia/UEMS.

SANTOS, L. A. (2005). "Considerações sobre o ensino de Português como segunda língua a partir da experiência com professores wajãpi”. Cadernos de Educação Escolar Indígena - $3^{\circ}$ Grau indígena. Barra do Bugres: UNEMAT, v. 4, n. 1.

SWAIN, Merrill. (1986). "Bilinguismo sem lágrimas". In: CUMMINS, J. e SWAIN, Merril Bilingualism in Education: aspects of theory, research and practice. Tradução: Wilmar R. D'angelis, 8 PP. Londres: Longman. 